\title{
ESTUDO DAS VAZÕES DE MANGUEIRAS DE INCÊNDIO: DETERMINAÇÃO DOS LIMITES CONSIDERANDO A CAPACIDADE FÍSICA
}

\author{
Rogério Lima de Araújo
}

\begin{abstract}
Resumo
Analisa as vazões do sistema de proteção contra incêndios por hidrante, sob a ótica das forças de propulsão por elas geradas, determinando de forma experimental os limites seguros para operação, considerando a capacidade física dos usuários. Aplica o Princípio Físico da Lei de Conservação do Momento Linear e determina a equação de propulsão das mangueiras de incêndio. De forma experimental comprova a validade da equação para o cálculo das forças de propulsão geradas pelas mangueiras de incêndio. Estabelece por análise do peso médio brasileiro e experiência com alunos bombeiros um limite seguro para operação de mangueiras de incêndio, como força de propulsão máxima segura a ser operada por um ou dois operadores. Com o termo força de propulsão da equação calcula as forças geradas pelas vazões comuns de operações e as estabelecidas na NBR 13714 (2000), constatando que as vazões dos maiores riscos de incêndio ultrapassam o limite estabelecido como seguro, entre 9,5 e 74,5\%. Conclui que a equação da força de propulsão de mangueiras de incêndio se constitui numa ferramenta útil para mensurar forças de propulsão.
\end{abstract}

Palavras-chave: Vazão de hidrante. Hidrante. Incêndio. Mangueira de incêndio.

\begin{abstract}
Analyzes the flow of the fire protection system by the standard hydrant, from the perspective of the propulsion forces they generate, experimentally determining the limits for safe operation, considering physical capacity of users. Apply the Principle of Physical Law of Conservation of Linear Momentum equation and determines the propulsion of the fire hoses. Experimentally prove the validity of the equation for calculating the thrust generated by fire hoses. Established by analysis of the weight average brazilian and experiment with a fire students safe limit for operation of fire hoses, such as thrust maximum safe to be operated by one or two operators. The term thrust of the equation calculates the forces generated by some flows and the established in NBR 13714 (2000), noting that the flow rates of the major fire hazards exceed the limit established as safe, between 9.5 and $74.5 \%$. It concludes that the equation of the thrust of fire hoses constitutes a useful tool to measure forces of thrust.
\end{abstract}

Key words: Flow hydrant. Hydrant. Fire. Fire hose. 
Revista Científica do Corpo de Bombeiros Militar de Pernambuco

XVIII Seminário Nacional de Bombeiros - Foz do Iguaçu PR

Vol.04 No11 - Edição Especial XVIII SENABOM - ISSN 2359-4829

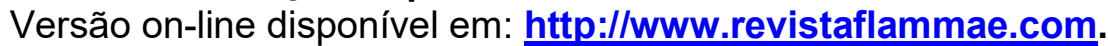

INTRODUÇÃO

Quando se faz o combate a incêndio com a utilização de água, a forma de lançar este agente extintor é pela utilização de mangueiras de incêndio e esguichos. Esta ação provoca uma força de propulsão, que pode ser estudada pela mesma lei física da propulsão de foguetes. Quanto mais água for lançada maior será esta força que age contrária à direção do jato.

$\mathrm{Na}$ doutrina de combate a incêndios brasileira não é comum encontrar faixas de vazões seguras para operação das mangueiras de incêndio, muito menos limites de vazões para operação com segurança. Observa-se uma grande dificuldade por parte dos bombeiros e demais profissionais de engenharia no dimensionamento das redes de hidrantes, principalmente quanto às vazões mínimas e máximas, e nas viaturas de incêndio, procura-se por empirismo respeitar alguns limites de segurança.

Não raramente, durante os anos de serviço no Corpo de Bombeiros, o autor ouviu relatos de bombeiros que se depararam com uma situação de risco ao testar os hidrantes de sistemas preventivos de estabelecimentos, e em algumas situações, o próprio autor pôde comprovar tal situação, podendo causar um acidente por descontrole na operação da mangueira de incêndio.

Neste contexto, ficam as seguintes perguntas: as vazões estabelecidas nos Códigos de Segurança contra Incêndio e Pânico oferecem total segurança? Há diferença na segurança de se operar estas vazões com esguichos de ângulo ajustável em comparação com o jato compacto?

Assim buscou-se Determinar de forma experimental os limites seguros de vazões para operação de mangueiras de incêndio por bombeiros e brigadistas do sistema fixo de proteção contra incêndios por hidrantes e viaturas de combate; Traçar um comparativo de forças de propulsão nos esguichos de jato compacto com os de ângulo ajustável; Propor limites de vazão para operação, estabelecendo o número recomendado de operadores.

A determinação experimental dos limites de vazão permitirá à prevenção de incêndios estabelecer em norma vazões mais precisas e adequadas aos riscos, atendendo 
Revista Científica do Corpo de Bombeiros Militar de Pernambuco

XVIII Seminário Nacional de Bombeiros - Foz do Iguaçu PR

Vol.04 N011 - Edição Especial XVIII SENABOM - ISSN 2359-4829

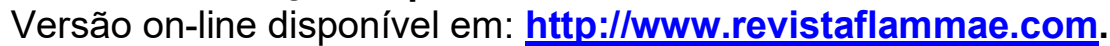

parâmetros de segurança para os usuários, possibilitando à engenharia de incêndio melhor dimensionamento dos sistemas preventivos contra incêndios. Com isso, também será possível trabalhar com mais segurança nas operações de combate a incêndio a partir de viaturas de combate, conhecendo melhor os limites de segurança para operação.

\section{Fundamentação Teórica}

A base teórica deste estudo encontra amparo em leis da Física e em normas brasileiras e internacionais que tratam do assunto. Pela $2^{\mathrm{a}}$ Lei de Newton e sua aplicação a sistemas de partículas, adaptando-se a equação de propulsão de foguetes para propulsão de mangueiras de incêndio, foi possível obter uma equação para mensurar a força de propulsão nas mangueiras de incêndio com as vazões estabelecidas em normas e que são usualmente utilizadas nas operações de combate a incêndios.

$F_{\text {prop. }}=\Delta \mathrm{m} / \Delta \mathrm{t} \times \mathbf{Q} / \mathbf{A}(1)$

Em que:

$F_{\text {prop. força de propulsão em } \mathrm{N}}$

$Q$ vazão $\mathrm{em} \mathrm{m}^{3} / \mathrm{s}$

$\Delta \mathbf{m} / \Delta \mathbf{t}$ vazão volumétrica convertida em vazão mássica em $\mathrm{Kg} / \mathrm{s}$

A área da secção transversal do requinte do esguicho $\mathrm{em}^{2}$

\section{Pressupostos de Capacidade Física para Operação de Mangueiras de Incêndio}

Foi considerado neste trabalho que os usuários não possuem treinamento para operação de hidrantes, desenvolvendo-se os cálculos dos limites seguros das vazões com base no menor peso médio do brasileiro com idade de trabalho de acordo com pesquisa desenvolvida pelo IBGE (2009), tratando-se, portanto, do peso médio da faixa etária feminina entre 18 e 64 anos, com peso de $60 \mathrm{Kgf}$. Para o cálculo do peso foi utilizada a equação da força peso considerando a aceleração da gravidade média na América do Sul, 9,80 m/s² (AZEVEDO NETTO et al. 1998, p. 7). 
Revista Científica do Corpo de Bombeiros Militar de Pernambuco

XVIII Seminário Nacional de Bombeiros - Foz do Iguaçu PR

Vol.04 No11 - Edição Especial XVIII SENABOM - ISSN 2359-4829

Versão on-line disponível em: http://www.revistaflammae.com.

A medição da força dos usuários do sistema preventivo seria muito difícil de determinar, por abranger públicos dos mais variados, desde leigos despreparados fisicamente até bombeiros profissionais que possuem treinamento e maior condicionamento físico. Da experiência do próprio autor como instrutor do Curso de Formação de Soldados do $4^{\circ}$ Grupamento de Bombeiros de Cascavel, no ano de 2010, em que ministrou treinamentos práticos de operação de mangueiras de incêndio para 49 civis leigos que recém haviam ingressados na Corporação, pode-se atribuir alguns pressupostos que ajudam nesta determinação.

Após o estudo deste público, foi estabelecida uma força máxima de 20 Kgf para operação de uma mangueira de incêndio, do sexo feminino ou masculino, dentro da faixa etária de trabalho. Esta força corresponde a $33 \%$ do peso médio brasileiro do sexo feminino e a $\mathbf{2 9 \%}$ do sexo masculino, ambos na faixa etária de 18 a 64 anos (IBGE, 2009). Tal limite de força se constitui aproximadamente 40\% menor em relação à força de propulsão suportada pelos alunos soldado.

O limite acima estabelecido é uma referência para o desenvolvimento do presente trabalho e não se constitui uma regra. Buscou-se um valor razoável dentro dos aspectos da quantidade de água que é necessária para o combate a incêndio, isto com base no que já é exigido pelas normas de prevenção de incêndios, e a segurança dos usuários, com margem de segurança em relação à capacidade física dos operadores, visto que as situações reais de combate a incêndio são as mais diversas, podendo ocorrer à noite, dificuldades de respiração e visibilidade comprometidas pela fumaça, piso molhado e escorregadio e tantos outros fatores complicadores.

\section{Metodologia}

A pesquisa para determinação dos limites seguros das vazões do sistema fixo de proteção contra incêndios por hidrantes pode ser classificada quanto aos fins como exploratória, utilizando o método experimental, numa abordagem quantitativa.

Procurou-se estabelecer uma seqüência metodológica para buscar responder ao problema levantado pela pesquisa e atingir seus objetivos. Assim, buscou-se primeiro 
validar a equação da força de propulsão das mangueiras de incêndios (equação 1) pelo método experimental. Uma vez validada a equação, ela foi utilizada para calcular as forças de propulsão que poderiam ser geradas pelas vazões comumente utilizadas nas normas preventivas do Brasil e da ABNT. Com os cálculos destas forças fez-se uma análise comparativa com o limite de força de propulsão estabelecido nos pressupostos de capacidade física dos usuários em operar as mangueiras de sistemas de hidrantes. Ainda na análise, foi realizado um comparativo dos resultados obtidos para as forças de propulsão dos esguichos de ângulo ajustável com os de jato compacto ou sólido. $\mathrm{Na}$ sequência, propuseram-se vazões que respeitassem o limite de força estabelecido além de outras proposições constantes nos pressupostos de capacidade física.

A validação da equação de propulsão das mangueiras de incêndio pelo método experimental ocorreu da seguinte forma:

a) Foi desenvolvido pelo autor um arranjo experimental que possibilitou mensurar as forças de propulsão das mangueiras de incêndio com experimentação das vazões estabelecidas na norma de prevenção de incêndios e da ABNT. As medidas foram todas comparadas com as previsões teóricas das forças de propulsão estabelecidas para cada vazão, medindo-se as vazões pelo Tubo de Pitot;

b) O arranjo experimental foi constituído de uma estrutura metálica tubular, com uma plataforma deslizante, que permitiu a leitura da força de propulsão por intermédio de uma célula de carga instalada na parte de trás do arranjo, conforme indica a figura 1 . 
Revista Científica do Corpo de Bombeiros Militar de Pernambuco

XVIII Seminário Nacional de Bombeiros - Foz do Iguaçu PR

Vol.04 No11 - Edição Especial XVIII SENABOM - ISSN 2359-4829

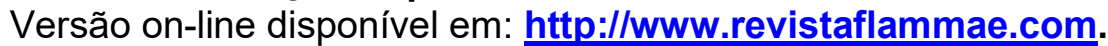

Figura 1 - Foto do arranjo experimental montado, com célula de carga e display digital

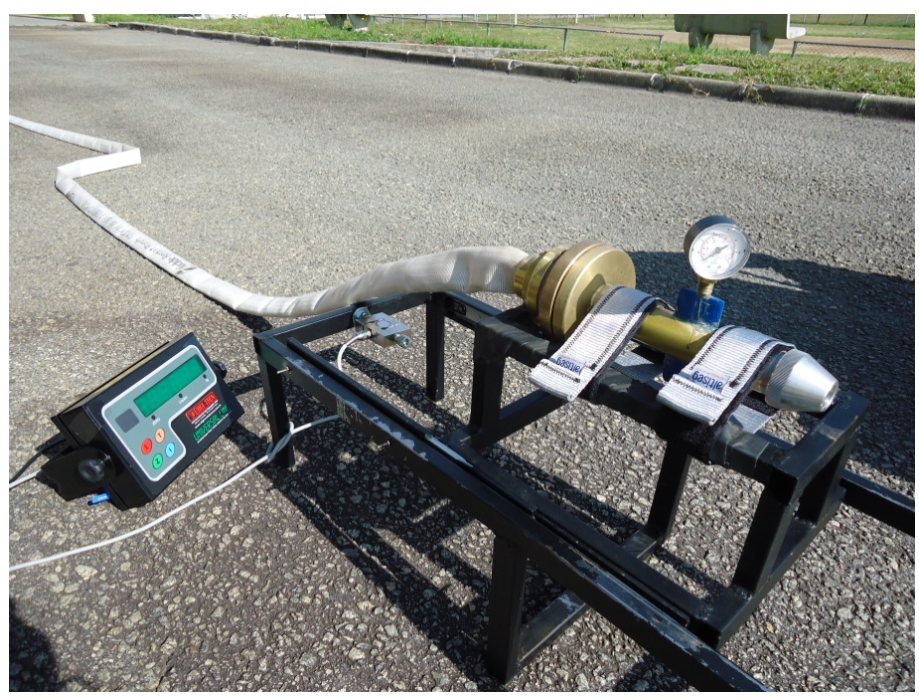

Fonte: Autor (2011)

c) Ele foi projetado para que a força de propulsão gerada na saída da água pelo esguicho fosse transferida para a célula de carga por intermédio da plataforma móvel, que conectada a um painel digital fez a leitura com uma precisão de $\pm 0,025 \mathrm{Kgf}$. Para que esta transferência ocorresse, bastou fixar de forma alinhada e nivelada o esguicho a esta plataforma;

d) Todas as medidas de pressão eram conferidas por Tubo de Pitot nas saídas dos esguichos de jato compacto. Inicialmente tais medições foram conferidas por dois destes aparelhos, para se ter maior confiabilidade nos resultados. Ressalta-se que foi verificado o laudo de calibração de ambos e se encontravam dentro da validade. Para os esguichos de jato ajustável foi lida somente a pressão do manômetro da viatura, com as devidas correções de perda de carga e possível diferença entre o manômetro da viatura e do Tubo de Pitot;

e) As forças de propulsão eram calculadas instantaneamente por intermédio da tabulação dos dados em planilha do Excel, sendo estudadas na seqüência para se verificar a confiabilidade das medidas. 


\section{DESENVOLVIMENTO}

Os resultados obtidos foram divididos em três partes e analisados para seguir o encaminhamento metodológico: $1^{\mathrm{a}}$ parte - medidas das forças externas e análise do quanto interferiram na medição das forças de propulsão; $2^{\mathrm{a}}$ parte - medidas das forças de propulsão das mangueiras de incêndio, com análise de validação da equação ( 2 ); $3^{\text {a }}$ parte - cálculo das forças de propulsão para algumas vazões utilizadas pelas normas dos Corpos de Bombeiros do Brasil e da Associação Brasileira de Normas Técnicas ABNT, com emprego da equação 1 .

\section{Resultados e Análise das Forças Externas}

Como já explicado na metodologia, a maior dificuldade encontrada na medição das forças de propulsão foi a força de resistência oferecida pelas mangueiras de incêndio. Para obter a confiabilidade das medidas da força de propulsão foi necessário estudar este comportamento. Abaixo se encontra a tabela $1 \mathrm{com}$ as medidas da força de resistência encontrada para as mangueiras de 38 e $63 \mathrm{~mm}$, sobre piso de concreto.

TABELA 1 - Resultados da força de resistência das mangueiras de incêndio de 38 e $63 \mathrm{~mm}$

\begin{tabular}{ccc}
$\begin{array}{c}\text { Pressão } \\
\text { estática } \\
\left(\mathrm{Kgf} / \mathrm{cm}^{2}\right)\end{array}$ & $\begin{array}{c}\text { Força de resistência } \\
\text { mangueira de } 38 \mathrm{~mm} \\
(\mathrm{Kgf})\end{array}$ & $\begin{array}{c}\text { Força de resistência } \\
\text { mangueira de } 63 \mathrm{~mm} \\
(\text { Kgf })\end{array}$ \\
\hline 1,0 & 6,00 & 21,60 \\
2,5 & 6,55 & 23,00 \\
5,0 & 7,05 & 27,75 \\
7,0 & 8,43 & 33,40 \\
10,0 & 11,50 & 44,15 \\
\hline
\end{tabular}

Nota: As forças foram medidas com mangueiras de $20 \mathrm{~m}$ de comprimento, do tipo II, sobre piso de concreto bruto.

Fonte: Autor (2011)

Para entendimento do comportamento destas forças externas foram traçados dois gráficos da força em relação à pressão, conforme abaixo se apresentam. 
Revista Científica do Corpo de Bombeiros Militar de Pernambuco

XVIII Seminário Nacional de Bombeiros - Foz do Iguaçu PR

Vol.04 No11 - Edição Especial XVIII SENABOM - ISSN 2359-4829

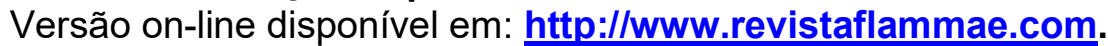

GRÁFICO 1 - Força de resistência mangueira de $38 \mathrm{~mm}$ (Kgf) em função da pressão estática $\left(\mathrm{Kgf} / \mathrm{cm}^{2}\right)$, referente tabela 1

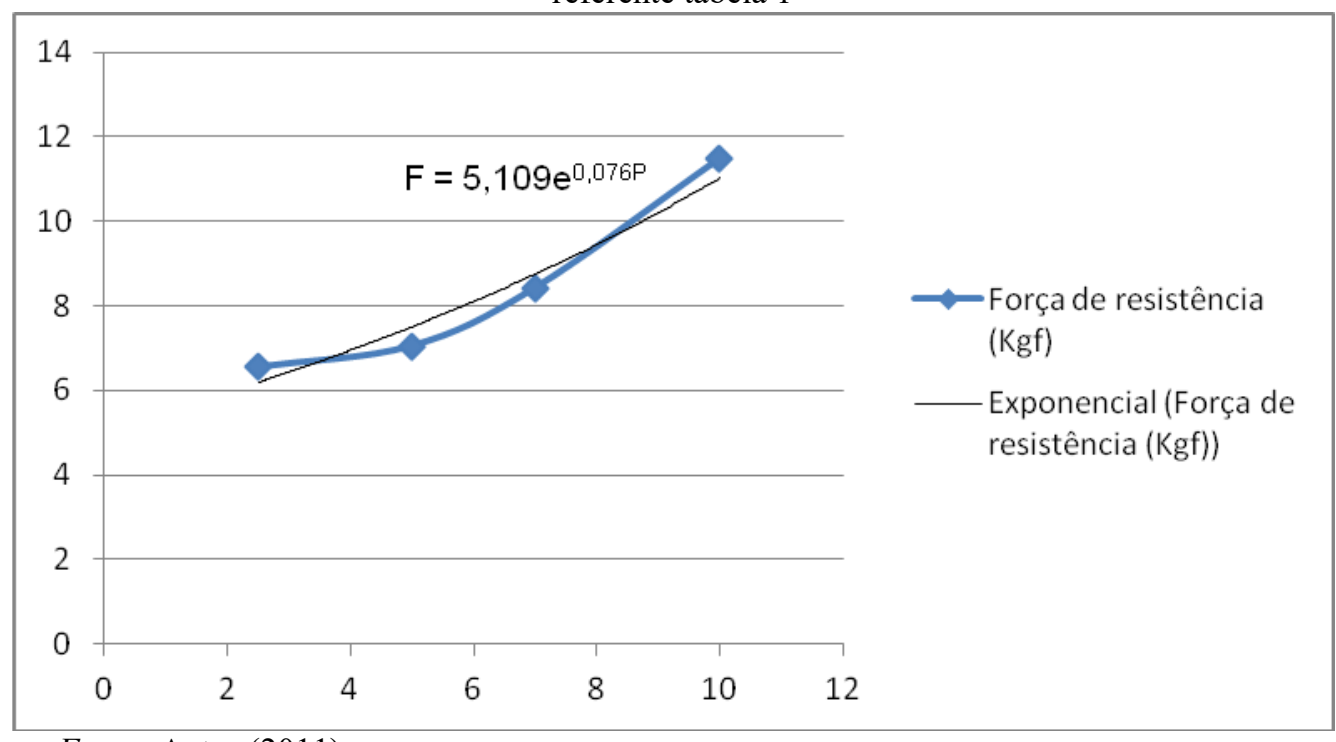

Fonte: Autor (2011)

GRÁFICO 2 - Força de resistência mangueira de $63 \mathrm{~mm}(\mathrm{Kgf})$ em função da pressão estática $\left(\mathrm{Kgf} / \mathrm{cm}^{2}\right)$, referente tabela 2

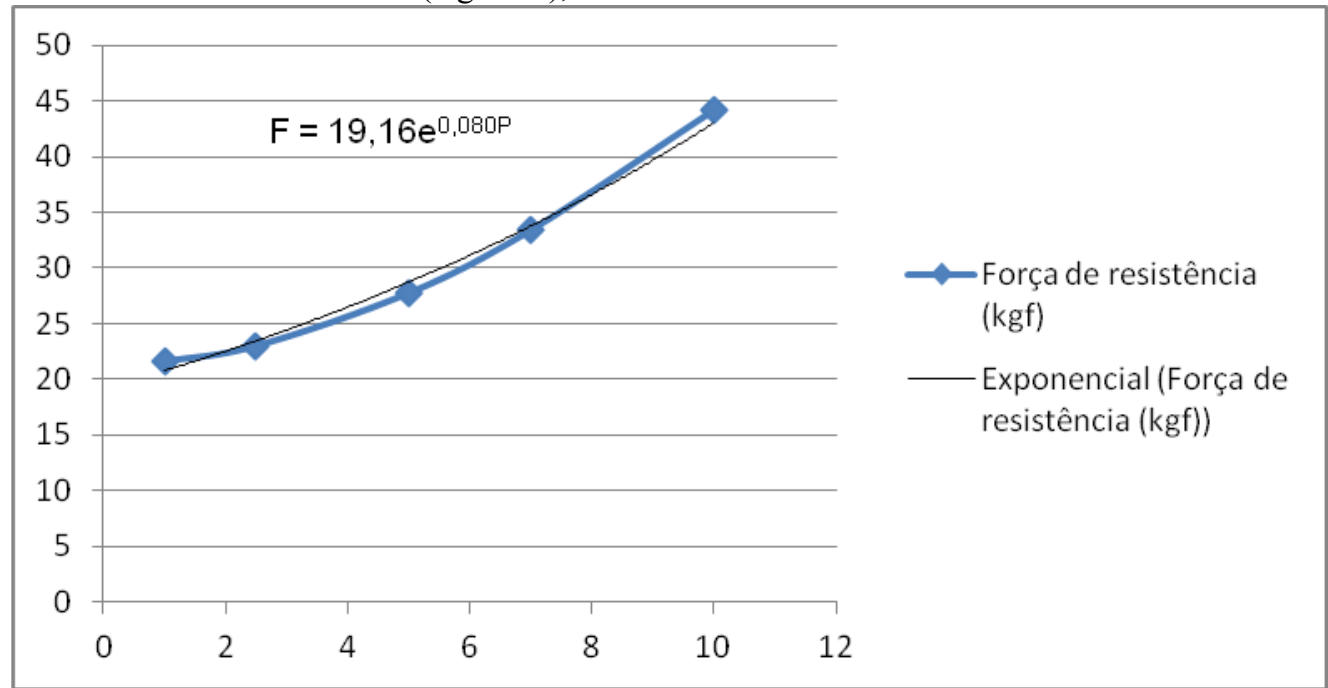

Fonte: Autor (2011)

As equações das funções exponenciais dos gráficos 1 e 2 são específicas deste experimento, não sendo uma generalização da força externa, que por análise da montagem experimental pode-se afirmar que se deve à força de resistência do material ao ser pressurizado, somada à força de atrito entre a mangueira e o solo. Para se ter uma generalização, seriam necessárias muitas medidas em diferentes tipos de terreno, pois para cada tipo de interação dos materiais da mangueira e do solo ter-se-á uma força 
diferente, devido às influências da força de atrito. Os dados acima apresentados são meramente um indicativo da existência desta força, que embora tenha influenciado no resultado das medidas da força de propulsão das mangueiras de incêndio ajudam a entender as diferenças das medidas da força real medida e da previsão teórica. A função exponencial foi a que melhor descreveu o comportamento desta força, pois pela análise desta função tem-se que quando a pressão aumenta bastante a força de resistência tende ao infinito. Para se imaginar como isto ocorreria, basta imaginar que para pressões elevadas a mangueira de incêndio tende a se comportar como uma tubulação rígida e não mais flexível.

\section{Resultados e Análise das Forças de Propulsão das Mangueiras de Incêndio}

Os resultados das medidas das forças de propulsão estão organizados por tipo de esguicho, e no caso dos esguichos de jato compacto, por diâmetro do requinte. Também foram realizadas medições com mangueiras de $38 \mathrm{~mm}$ e $63 \mathrm{~mm}$.

Todas as tabelas de resultados serão acompanhadas de gráficos e análise para compreensão do fenômeno estudado.

Antes da apresentação, faz-se necessário esclarecer que a previsão teórica da força de propulsão das mangueiras de incêndio foi feita pela obtenção da vazão na saída dos esguichos de jato compacto com os requintes de 13, 19 e $25 \mathrm{~mm}$, utilizando as mangueiras de 38 e $63 \mathrm{~mm}$. Estas vazões foram obtidas utilizando o processo expedito de cálculo da vazão para bocais, trazido por Azevedo Netto et al. (1998, p. 75), adaptada às unidades de pressão e vazão mais utilizadas pelos profissionais de engenharia e bombeiros, ficando com o seguinte formato:

$Q=0,654 \times D^{2} \times(P)^{1 / 2}(2)$

Em que:

Q vazão em 1/min

D diâmetro do requinte do esguicho em $\mathrm{mm}$

P pressão lida com tubo de pitot na saída do esguicho em $\mathrm{Kgf} / \mathrm{cm}^{2}$

Foram também comprovadas tais vazões por outras equações com variações insignificantes para o presente estudo. Com os resultados das vazões foi aplicada a 
equação da propulsão das mangueiras de incêndio (equação 2), conforme demonstrado na fundamentação teórica, equação esta que com dados de vazão e diâmetro do requinte pode-se calcular a força de propulsão.

Para os esguichos de jato ajustável foi estimado um diâmetro equivalente com base nos resultados obtidos nos esguichos de jato compacto, pois no jato ajustável não é possível obter a pressão dinâmica na saída do esguicho por intermédio do tubo de pitot. Uma das maneiras de obter a vazão nestes esguichos seria por medir o volume de água contra o tempo em um reservatório de volume conhecido, porém, foi testada pelo autor tal prática não obtendo valores precisos, pois a perda de carga aumenta conforme se aumenta a pressão e demandaria muito tempo e repetição de medidas para se aproximar a um valor confiável. Já que se tinham as medidas confiáveis da força de propulsão gerada no arranjo experimental, optou-se por aproveitar estes resultados para se determinar um diâmetro equivalente aos esguichos de ângulo ajustável para então poder utilizar a equação da força de propulsão.

Com a tabela 2 inicia-se a apresentação dos resultados para as forças de propulsão medidas com o arranjo experimental e sua previsão teórica.

TABELA 2 - Resultados da força de propulsão para esguicho tipo agulheta com requinte de $13 \mathrm{~mm}$, mangueira de $38 \mathrm{~mm}$

\begin{tabular}{ccccccc}
\hline $\begin{array}{c}\text { Pressão } \\
\text { Bomba } \\
\left(\mathrm{Kgf} / \mathrm{cm}^{2}\right)\end{array}$ & $\begin{array}{c}\text { Pressão } \\
\text { Tubo de Pitot } \\
\left(\mathrm{Kgf} / \mathrm{cm}^{2}\right)\end{array}$ & $\begin{array}{c}\text { Diâmetro } \\
\text { Requinte } \\
(\mathrm{mm})\end{array}$ & $\begin{array}{c}\text { Vazão } \\
(\mathrm{l} / \mathrm{min})\end{array}$ & $\begin{array}{c}\text { Força } \\
\text { Teórica } \\
(\text { Kgf })\end{array}$ & $\begin{array}{c}\text { Força } \\
\text { Medida } \\
(\text { Kgf })\end{array}$ & $\begin{array}{c}\text { Diferença } \\
\text { Teo/Med. } \\
\%\end{array}$ \\
\hline 3,2 & 3,4 & 13 & 204 & 8,9 & 8,70 & 1,91 \\
3,8 & 4,3 & 13 & 229 & 11,2 & 10,95 & 2,38 \\
5,0 & 5,5 & 13 & 259 & 14,3 & 13,85 & 3,47 \\
6,0 & 6,5 & 13 & 282 & 17,0 & 16,10 & 5,05 \\
7,5 & 8,0 & 13 & 313 & 20,9 & 19,70 & 5,60 \\
8,4 & 8,9 & 13 & 330 & 23,2 & 21,55 & 7,18 \\
\hline
\end{tabular}

Fonte: Autor (2011)

Ao analisar os dados da força de propulsão medida para o requinte de $13 \mathrm{~mm} \mathrm{e}$ mangueira de $38 \mathrm{~mm}$, conforme demonstra a tabela 3, verifica-se uma diferença entre a força medida e a previsão teórica com crescimento da diferença acompanhando o 
Revista Científica do Corpo de Bombeiros Militar de Pernambuco

XVIII Seminário Nacional de Bombeiros - Foz do Iguaçu PR

Vol.04 N011 - Edição Especial XVIII SENABOM - ISSN 2359-4829

Versão on-line disponível em: http://www.revistaflammae.com.

aumento da pressão. Estas diferenças devem-se à resistência pelo enrijecimento da mangueira de incêndio e pelo aumento da pressão, colaborada pela força de atrito que atua sobre todo sistema caminhão e mangueira, tornando-se uma força externa que age contrária à força de propulsão, conforme já foi explicado. $\mathrm{O}$ gráfico abaixo demonstra $\mathrm{o}$ comportamento destas forças.

GRÁFICO 3 - Força de propulsão (Kgf) em função da vazão (1/min), referente tabela 3, mangueira de $38 \mathrm{~mm}$, requinte de $13 \mathrm{~mm}$

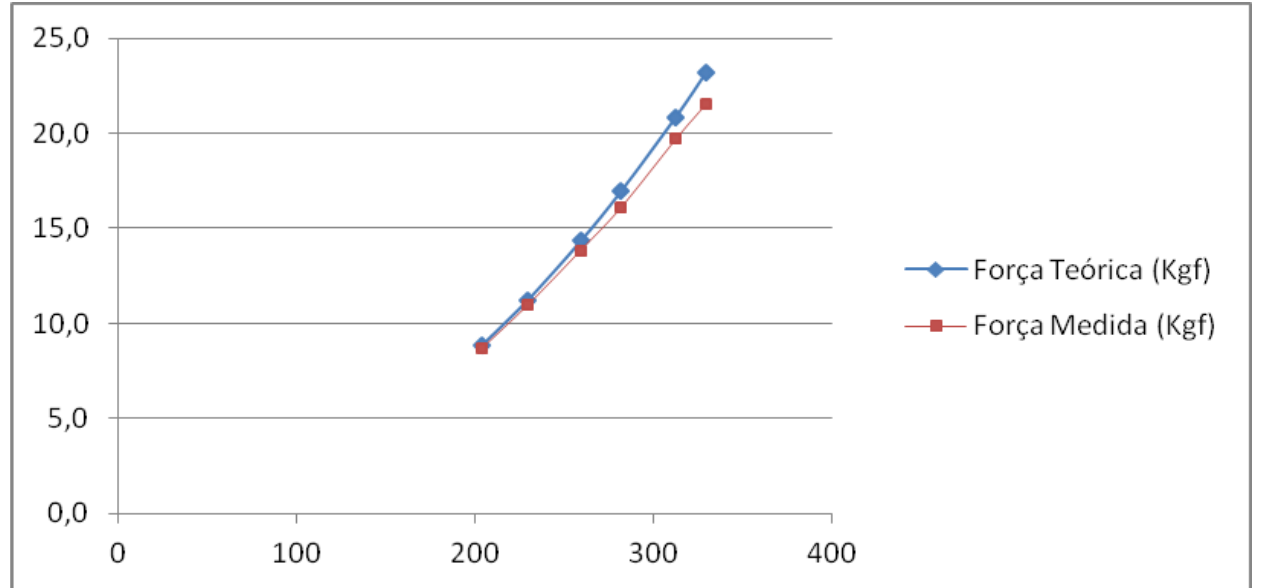

Fonte: Autor (2011)

O gráfico 3 mostra o crescimento desta diferença podendo ser observada pelo distanciamento da curva da força medida em relação à força teórica calculada com a utilização da equação 2, com as pressões obtidas pela leitura na saída do esguicho com o Tubo de Pitot.

Trazem-se, na seqüência, os resultados da tabela 3 , relativos às medidas realizadas com o esguicho de jato compacto, com requinte de $19 \mathrm{~mm}$ e mangueira de 63 $\mathrm{mm}$. 
Revista Científica do Corpo de Bombeiros Militar de Pernambuco

XVIII Seminário Nacional de Bombeiros - Foz do Iguaçu PR

Vol.04 No11 - Edição Especial XVIII SENABOM - ISSN 2359-4829

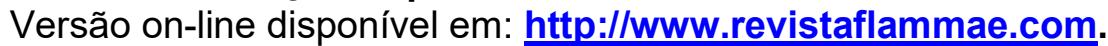

TABELA 3 - Resultados da força de propulsão para esguicho tipo agulheta com requinte de $19 \mathrm{~mm}$, mangueira de $63 \mathrm{~mm}$

\begin{tabular}{ccccccc}
\hline $\begin{array}{c}\text { Pressão } \\
\text { Bomba } \\
\text { (Kgf/cm2 })\end{array}$ & $\begin{array}{c}\text { Pressão } \\
\text { Tubo de Pitot } \\
(\text { Kgf/cm2 })\end{array}$ & $\begin{array}{c}\text { Diâmetro } \\
\text { Requinte } \\
(\mathrm{mm})\end{array}$ & $\begin{array}{c}\text { Vazão } \\
(\mathrm{l} / \mathrm{min})\end{array}$ & $\begin{array}{c}\text { Força } \\
\text { Teórica } \\
(\text { Kgf })\end{array}$ & $\begin{array}{c}\text { Força } \\
\text { Medida } \\
(\text { Kgf })\end{array}$ & $\begin{array}{c}\text { Diferença } \\
\text { Teo/Med. } \\
\%\end{array}$ \\
\hline 3,7 & 4,2 & 19 & 484 & 23,4 & 15,95 & 31,85 \\
5,1 & 5,3 & 19 & 544 & 29,5 & 21,05 & 28,73 \\
6 & 6,2 & 19 & 588 & 34,5 & 24 & 30,53 \\
7 & 7,2 & 19 & 634 & 40,1 & 27,7 & 30,96 \\
8,6 & 8,6 & 19 & 692 & 47,9 & 33,25 & 30,62 \\
10 & 10 & 19 & 747 & 55,7 & 37,4 & 32,88 \\
11 & 11 & 19 & 783 & 61,3 & 38,4 & 37,35 \\
\hline
\end{tabular}

Fonte: Autor (2011)

Observa-se que a diferença entre a força medida e a teórica já se iniciou maior em relação aos dados anteriores. Isto se deve à diferença entre a força de resistência da mangueira de $38 \mathrm{~mm}$ e a de $63 \mathrm{~mm}$, que é maior, como já foi visto no item de análise da força de resistência.

Na seqüência, a tabela 4 apresenta os resultados para as forças de propulsão medidas com esguicho de jato compacto, com requinte de $25 \mathrm{~mm}$ e mangueira de 63 $\mathrm{mm}$.

TABELA 4 - Resultados da força de propulsão para esguicho tipo agulheta com requinte de $25 \mathrm{~mm}$, mangueira de $63 \mathrm{~mm}$

\begin{tabular}{ccccccc}
\hline $\begin{array}{c}\text { Pressão } \\
\text { Bomba } \\
\left(\mathrm{Kgf} / \mathrm{cm}^{2}\right)\end{array}$ & $\begin{array}{c}\text { Pressão } \\
\text { Tubo de Pitot } \\
\left(\mathrm{Kgf} / \mathrm{cm}^{2}\right)\end{array}$ & $\begin{array}{c}\text { Diâmetro } \\
\text { Requinte } \\
(\mathrm{mm})\end{array}$ & $\begin{array}{c}\text { Vazão } \\
(1 / \mathrm{min})\end{array}$ & $\begin{array}{c}\text { Força } \\
\text { Teórica } \\
(\mathrm{Kgf})\end{array}$ & $\begin{array}{c}\text { Força } \\
\text { Medida } \\
(\text { Kgf })\end{array}$ & $\begin{array}{c}\text { Diferença } \\
\text { Teo/Med. } \\
\%\end{array}$ \\
\hline 3,4 & 3,4 & 25 & 754 & 32,8 & 23,0 & 29,9 \\
5,5 & 5,5 & 25 & 959 & 53,1 & 38,0 & 28,4 \\
6,5 & 6,5 & 25 & 1042 & 62,7 & 43,7 & 30,3 \\
10,5 & 10 & 25 & 1293 & 96,5 & 70,0 & 27,4 \\
\hline
\end{tabular}

Fonte: Autor (2011)

Passa-se, na sequência, a trazer os resultados das medidas de força com a utilização dos esguichos de jato ajustável. 
Revista Científica do Corpo de Bombeiros Militar de Pernambuco

XVIII Seminário Nacional de Bombeiros - Foz do Iguaçu PR

Vol.04 No11 - Edição Especial XVIII SENABOM - ISSN 2359-4829

Versão on-line disponível em: http://www.revistaflammae.com.

TABELA 5 - Resultados da força de propulsão para esguicho de ângulo ajustável de $63 \mathrm{~mm}$, mangueira de $63 \mathrm{~mm}$

\begin{tabular}{cccccc}
\hline $\begin{array}{c}\text { Pressão } \\
\text { Bomba } \\
\left(\mathrm{Kgf} / \mathrm{cm}^{2}\right)\end{array}$ & $\begin{array}{c}\text { Diâmetro* } \\
\text { equivalente } \\
(\mathrm{mm})\end{array}$ & $\begin{array}{c}\text { Vazão } \\
(1 / \mathrm{min})\end{array}$ & $\begin{array}{c}\text { Força } \\
\text { Teórica } \\
\text { (Kgf) }\end{array}$ & $\begin{array}{c}\text { Força } \\
\text { Medida } \\
(\text { Kgf) }\end{array}$ & $\begin{array}{c}\text { Diferença } \\
\text { Teo/Med. } \\
\%\end{array}$ \\
\hline 3,8 & 17 & 368 & 17,0 & 16,4 & 3,3 \\
5,2 & 17 & 431 & 23,2 & 20,0 & 13,8 \\
6,7 & 17 & 489 & 29,9 & 26,0 & 13,0 \\
8,5 & 17 & 551 & 37,9 & 32,5 & 14,3 \\
9,5 & 17 & 583 & 42,4 & 35,5 & 16,2 \\
11,3 & 17 & 635 & 50,4 & 42,0 & 16,7 \\
13,4 & 17 & 692 & 59,8 & 50,0 & 16,4 \\
14,2 & 17 & 712 & 63,3 & 52,0 & 17,9 \\
\hline
\end{tabular}

Nota: * Diâmetro equivalente obtido por experimentação da força de propulsão.

Fonte: Autor (2011)

Verifica-se comportamento parecido deste tipo de esguicho em relação aos de jato compacto. Constata-se ainda pela análise das diferenças entre as forças teóricas e as forças medidas pelo arranjo experimental, para os esguichos ajustáveis, que elas são menores quando comparadas às diferenças apresentadas pelas forças geradas pelos esguichos de jato compacto. Isto se deve, na opinião deste pesquisador, pelo fato deste tipo de esguicho possibilitar melhor ajuste do arranjo experimental para a coleta das medidas.

GRÁFICO 4 - Força de propulsão (Kgf) em função da vazão (1/min), referente tabela 5 - mangueira de $63 \mathrm{~mm}$, esguicho ajustável de $63 \mathrm{~mm}$

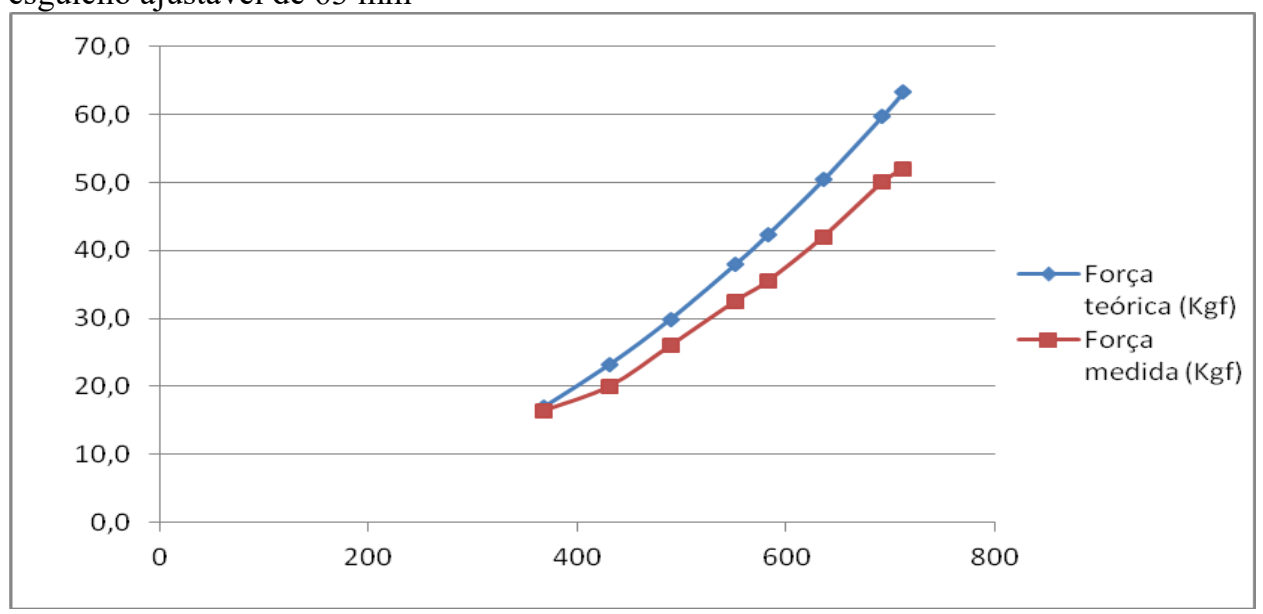

Fonte: Autor (2011) 
Observa-se também na curva da força medida leve tendência ao final em se estabilizar por interferência contrária da força de resistência da mangueira de incêndio.

A seguir, traz-se os dados do esguicho de jato ajustável do tipo pistola, verificando-se comportamento atípico aos até então apresentados. Observa-se que as diferenças entre as forças medidas e as teóricas foram muito pequenas como se pode ver na tabela 10 e em suas curvas no gráfico 12 .

TABELA 6 - Resultados da força de propulsão para esguicho tipo pistola ajustável de vazão constante de $38 \mathrm{~mm}$, mangueira de $38 \mathrm{~mm}$

\begin{tabular}{ccccccc}
\hline $\begin{array}{c}\text { Pressão } \\
\text { Bomba } \\
\left(\mathrm{Kgf} / \mathrm{cm}^{2}\right)\end{array}$ & $\begin{array}{c}\text { Pressão com } \\
\text { desconto da } \\
\text { perda de carga } \\
\left(\mathrm{Kgf} / \mathrm{cm}^{2}\right)\end{array}$ & $\begin{array}{c}\text { Diâmetro* } \\
\text { Equivalente } \\
(\mathrm{mm})\end{array}$ & $\begin{array}{c}\text { Vazão } \\
(1 / \mathrm{min})\end{array}$ & $\begin{array}{c}\text { Força } \\
\text { Teórica } \\
(\text { Kgf })\end{array}$ & $\begin{array}{c}\text { Força } \\
\text { Medida } \\
(\text { Kgf })\end{array}$ & $\begin{array}{c}\text { Diferença } \\
\text { Teo/Med. } \\
\%\end{array}$ \\
\hline 7,0 & 5,6 & 15,5 & 372 & 20,8 & 19,9 & 4,2 \\
8,5 & 6,8 & 15,5 & 410 & 25,2 & 24,9 & 1,3 \\
9,4 & 7,5 & 15,5 & 431 & 27,9 & 28,2 & $-0,9$ \\
10,4 & 8,2 & 15,5 & 450 & 30,5 & 30,0 & 1,5 \\
\hline
\end{tabular}

Nota: * Diâmetro equivalente obtido por experimentação da força de propulsão.

A pressão foi considerada com perda de carga média de $22 \%$, por observação das perdas em mesma condição com requinte de $19 \mathrm{~mm}$ (ver tabela 5).

Fonte: Autor (2011)

GRÁFICO 5 - Força de propulsão (Kgf) em função da vazão (1/min), referente tabela 10 - mangueira de $38 \mathrm{~mm}$, esguicho ajustável tipo pistola de $38 \mathrm{~mm}$

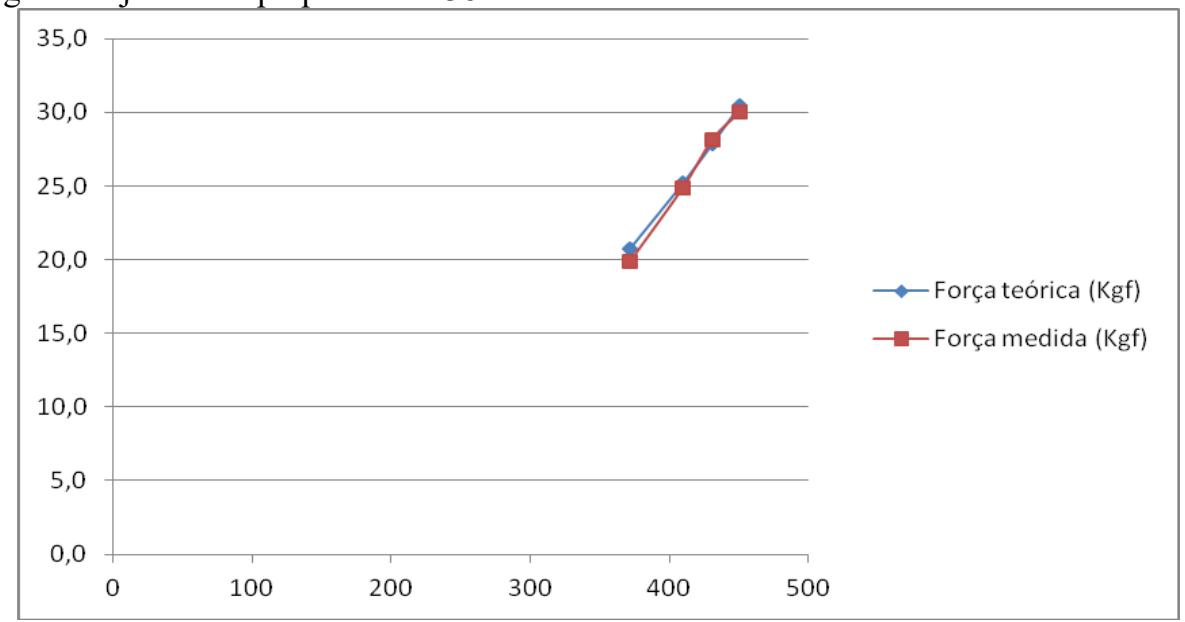

Fonte: Autor (2011)

Da análise do gráfico 5, acredita-se que tais diferenças ficaram minimizadas pelos dispositivos mais avançados de controle de jato que este tipo de esguicho possibilita quando comparado com o ajustável comum. Este esguicho tem registro 
Revista Científica do Corpo de Bombeiros Militar de Pernambuco

XVIII Seminário Nacional de Bombeiros - Foz do Iguaçu PR

Vol.04 No11 - Edição Especial XVIII SENABOM - ISSN 2359-4829

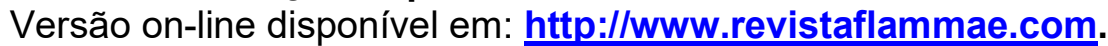

independente do ajuste do jato e trabalha a uma pressão a partir de $6,8 \mathrm{Kgf} / \mathrm{cm}^{2}$, fornecendo para uma mesma pressão vazão constante, independente do jato, o que não ocorre com o esguicho ajustável comum.

\section{Validade da equação de propulsão das mangueiras de incêndio}

Conforme já foi explanado na fundamentação teórica, a equação de propulsão da mangueira traz a aceleração que todo sistema caminhão, bombeiro e mangueira de incêndio poderiam ganhar ao expelir água. Ocorre que no caso real a força de atrito impede que o caminhão se desloque na direção contrária de saída da água, como ocorre analogamente com os foguetes que jogam combustível pelo processo de queima para uma direção e se deslocam para outra. Situação semelhante irá acontecer quando se usa a mangueira de incêndio de um hidrante, este não irá se deslocar, pois está fixo.

Como não há o deslocamento do caminhão de bombeiro na direção contrária, a mangueira de incêndio sofre uma força de resistência, além da resistência dela mesma pelo atrito com o solo. Por encontrar esta resistência do caminhão, a mangueira sofre uma compressão tendendo a se dobrar. Ocorre que ela se torna um duto semi - rígido pelo aumento da pressão interna, quanto maior a pressão, maior a resistência - ver gráficos 3 e 4. Tal comportamento constitui-se numa força externa que corresponde ao termo da equação $\Delta \mathrm{P} / \Delta \mathrm{t}$. Esta força não é estável, pois depende da pressão no interior da mangueira de incêndio. Somada a esta força tem-se a força de atrito, que também não é uma força estável e de fácil determinação. Neste trabalho procurou-se medir uma situação de atuação destas duas forças juntas, o que pode ser observado na tabela 2 e nos gráficos de 1 a 4. Pela análise dos gráficos, chegou-se à conclusão de que o aumento desta força se dá numa curva exponencial, ou seja, quanto mais se aumenta a pressão mais maior é o seu crescimento. Isto explica as aberturas acentuadas das curvas no final das medidas dos gráficos das forças de propulsão.

Fica, então, comprovada por medidas experimentais que a equação de propulsão de foguetes, adaptada à força de propulsão de mangueiras de incêndio é válida para o cálculo das forças de propulsão. Sua aplicabilidade é vasta, pois para 
Revista Científica do Corpo de Bombeiros Militar de Pernambuco

XVIII Seminário Nacional de Bombeiros - Foz do Iguaçu PR

Vol.04 No11 - Edição Especial XVIII SENABOM - ISSN 2359-4829

Versão on-line disponível em: http://www.revistaflammae.com.

qualquer vazão encontrada, basta saber o diâmetro do requinte do esguicho para se ter o valor da força de propulsão.

\section{Proposta de Limites Seguros para Vazões}

Com a aplicação da equação da força de propulsão e considerando o limite seguro estabelecido como referência de $20 \mathrm{Kgf}$, calcularam-se todas vazões máximas para que respeitassem o limite de segurança. Abaixo são apresentadas as tabelas com as propostas de vazões a partir do risco moderado, por verificar que as vazões do risco leve não ultrapassaram o limite seguro.

TABELA 7 - Proposta de vazões para o risco moderado

\begin{tabular}{|c|c|c|c|c|c|c|}
\hline $\begin{array}{l}\text { Tipo de } \\
\text { Esguicho }\end{array}$ & $\begin{array}{l}\text { Esguicho } \\
\text { diâmetro } \\
\qquad(\mathrm{mm})\end{array}$ & $\begin{array}{l}\text { Mangueira } \\
\text { diâmetro } \\
(\mathrm{mm})\end{array}$ & $\begin{array}{l}\text { Vazão } \\
\text { simples } \\
(1 / \mathrm{min})\end{array}$ & $\begin{array}{l}\text { Vazão } \\
\text { máxima } \\
\text { (1/min) }\end{array}$ & $\begin{array}{c}\text { F. Prop. } \\
\text { Vz. simples } \\
\text { (Kgf) }\end{array}$ & $\begin{array}{c}\text { F. Prop. } \\
\text { Vz. máxima } \\
(\mathrm{Kgf})\end{array}$ \\
\hline Jato compacto & 19 & 38 ou 63 & 400 & 440 & 16 & 19 \\
\hline Jato compacto & 25 & 38 ou 63 & 400 & 440 & 9 & 11 \\
\hline $\begin{array}{c}\text { Ajustável* } \\
\text { (storz 38mm) }\end{array}$ & 16 & 38 & 350 & 380 & 17 & 20 \\
\hline $\begin{array}{c}\text { Ajustável* } \\
(\text { storz 63mm) }\end{array}$ & 17 & 63 & 380 & 400 & 18 & 20 \\
\hline $\begin{array}{l}\text { Nota: } \quad * \\
\text { Fonte: }\end{array}$ & metro & alente & por & experim & do & prio \\
\hline
\end{tabular}

A seguir é apresentada a tabela com as propostas de vazões de risco elevado para os estabelecimentos que não tem brigada própria, e na sequência, para os que têm brigada própria. 
Revista Científica do Corpo de Bombeiros Militar de Pernambuco

XVIII Seminário Nacional de Bombeiros - Foz do Iguaçu PR

Vol.04 No11 - Edição Especial XVIII SENABOM - ISSN 2359-4829

Versão on-line disponível em: http://www.revistaflammae.com.

TABELA 8 - Proposta de vazões para o risco elevado - estabelecimentos sem brigada própria

\begin{tabular}{|c|c|c|c|c|c|c|}
\hline $\begin{array}{l}\text { Tipo de } \\
\text { Esguicho }\end{array}$ & $\begin{array}{l}\text { Esguicho } \\
\text { diâmetro } \\
\quad(\mathrm{mm})\end{array}$ & $\begin{array}{l}\text { Mangueira } \\
\text { diâmetro } \\
(\mathrm{mm})\end{array}$ & $\begin{array}{l}\text { Vazão } \\
\text { simples } \\
(1 / \mathrm{min})\end{array}$ & $\begin{array}{c}\text { Vazão } \\
\text { máxima } \\
(1 / \min )\end{array}$ & $\begin{array}{c}\text { F. Prop. } \\
\text { Vz. simples } \\
(\mathrm{Kgf})\end{array}$ & $\begin{array}{c}\text { F. Prop. } \\
\text { Vz. máxima } \\
(\mathrm{Kgf})\end{array}$ \\
\hline Jato compacto & 25 & 38 ou 63 & 500 & 550 & 14 & 17 \\
\hline Jato compacto & 32 & 38 ou 63 & 500 & 550 & 9 & 11 \\
\hline $\begin{array}{c}\text { Ajustável* } \\
\text { (storz 63mm) }\end{array}$ & 17 & 63 & 380 & 400 & 18 & 20 \\
\hline $\begin{array}{l}\text { Nota: } \quad * \\
\text { Fonte: }\end{array}$ & netro & lente & & experin & do & prio \\
\hline
\end{tabular}

TABELA 9 - Proposta de vazões para o risco elevado - estabelecimentos com brigada própria

\begin{tabular}{|c|c|c|c|c|c|c|c|c|}
\hline $\begin{array}{l}\text { Tipo } \\
\text { Esguicho }\end{array}$ & $\begin{array}{l}\text { Esguicho } \\
\text { diâmetro } \\
(\mathrm{mm})\end{array}$ & $\begin{array}{l}\text { Mangueira } \\
\text { diâmetro } \\
(\mathrm{mm})\end{array}$ & $\begin{array}{l}\text { Vazão } \\
\text { simples } \\
(1 / \mathrm{min})\end{array}$ & $\begin{array}{l}\text { Vazão } \\
\text { máxima } \\
(1 / \min )\end{array}$ & $\begin{array}{l}\text { F. } \\
\text { Vz. } \\
\text { (Kgf) }\end{array}$ & $\begin{array}{r}\text { Prop. } \\
\text { simples }\end{array}$ & $\begin{array}{l}\text { F. } \\
\text { Vz. } \\
\text { (Kgf) }\end{array}$ & $\begin{array}{l}\text { Prop. } \\
\text { máxima }\end{array}$ \\
\hline Jato compacto & 25 & 38 ou 63 & 550 & 600 & 17 & & 20 & \\
\hline Jato compacto & 32 & 38 ou 63 & 550 & 600 & 11 & & 13 & \\
\hline $\begin{array}{l}\text { Ajustável* } \\
\text { (storz 63mm) }\end{array}$ & 17 & 63 & 450 & 500 & 25 & & 30 & \\
\hline
\end{tabular}

Observa-se que todas as vazões respeitaram o limite de segurança para as forças de propulsão geradas pelas vazões de $20 \mathrm{Kgf}$, com exceção da proposta de risco elevado para estabelecimentos que sejam exigidos por norma a constituição de brigadas de incêndio, e mesmo assim, extrapolou somente no esguicho de ângulo ajustável que permite maior controle da vazão.

\section{CONCLUSÃO}

O estudo desenvolvido neste trabalho comprova que a equação de propulsão de foguetes, adaptada à propulsão de mangueiras de incêndio se constitui numa ferramenta para se mensurar as forças de propulsão geradas pelas mangueiras de incêndio dos sistemas de hidrantes ou de outros sistemas que utilizem mangueiras de incêndio.

A força de propulsão das mangueiras de incêndio é proporcional ao produto da vazão de massa pela vazão volumétrica e inversamente proporcional à área da seção 
Revista Científica do Corpo de Bombeiros Militar de Pernambuco

XVIII Seminário Nacional de Bombeiros - Foz do Iguaçu PR

Vol.04 No11 - Edição Especial XVIII SENABOM - ISSN 2359-4829

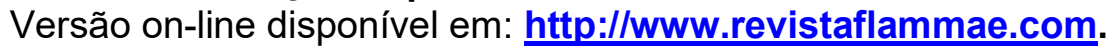

transversal do requinte dos esguichos $\left(\mathbf{F}_{\text {propulsão }}=\Delta \mathbf{m} / \Delta \mathbf{t} \times \mathbf{Q} / \mathbf{A}\right)$. Para os esguichos de ângulo ajustável foi estimado por observação experimental das forças de propulsão geradas por eles um diâmetro equivalente de $16 \mathrm{~mm}$ para o esguicho de $38 \mathrm{~mm}$ e de $17 \mathrm{~mm}$ para o esguicho de $63 \mathrm{~mm}$. Tais valores podem ter variação de acordo com o fabricante do esguicho. No experimento foram utilizados esguichos em uso pelo Corpo de Bombeiros do Paraná.

Com o emprego da equação de propulsão das mangueiras de incêndio foi possível estimar as forças geradas pelas vazões da norma preventiva normalmente utilizada pelos Copos de Bombeiros e da ABNT, NBR 13714 (2000), comparando-as com o limite de segurança para operação de mangueiras de incêndio de $20 \mathrm{Kgf}$, estabelecido com base em experiências práticas e análise do peso médio do brasileiro do sexo feminino e masculino, entre 18 e 64 anos. Da análise que se fez destas forças comprova-se que as vazões do risco moderado e elevado podem gerar forças acima do limite seguro variando de 28,2 a $49,1 \%$ para o risco moderado e de 9,5 a $74,5 \%$ para o risco elevado.

Diante do quadro acima, foram apresentadas propostas de vazões que respeitam o limite de segurança, variando entre 350 e 440 1/min para o risco moderado e 380 a 550 1/min para o risco elevado, sugerindo uma subclasse dentro do risco elevado para os estabelecimentos em que for exigida por norma a constituição de brigadas de incêndio próprias, podendo variar a vazão entre 450 e 600 1/min.

Conclui-se que a equação da força de propulsão de mangueiras de incêndio se constitui numa ferramenta útil para estimar forças de propulsão, possibilitando adequar vazões dos sistemas preventivos por hidrantes e de viaturas de combate a incêndio dentro do limite aceitável de segurança para a operação das mangueiras de incêndio, sejam por bombeiros, usuários leigos ou por profissionais da prevenção e combate a incêndios. 


\section{Revista FLAMMAE}

Revista Científica do Corpo de Bombeiros Militar de Pernambuco XVIII Seminário Nacional de Bombeiros - Foz do Iguaçu PR

Vol.04 No11 - Edição Especial XVIII SENABOM - ISSN 2359-4829

Versão on-line disponível em: http://www.revistaflammae.com.

\section{REFERÊNCIAS}

ASSOCIAÇÃO BRASILEIRA DE NORMAS TÉCNICAS. NBR 11861: Mangueiras de incêndio - Requisitos e métodos de ensaio. Rio de Janeiro, 1998.

ASSOCIAÇÃO BRASILEIRA DE NORMAS TÉCNICAS. NBR 5626: Instalação predial de água fria. Rio de Janeiro, 1999.

ASSOCIAÇÃO BRASILEIRA DE NORMAS TÉCNICAS. NBR 13714: Sistemas de hidrantes e de mangotinhos para combate a incêndio. Rio de Janeiro, 2000.

ASSOCIAÇÃO BRASILEIRA DE NORMAS TÉCNICAS. NBR 14870: Esguichos de jato regulável para combate a incêndio. Rio de Janeiro, 2002.

ASSOCIAÇÃO BRASILEIRA DE NORMAS TÉCNICAS. NBR 12779: Inspeção manutenção e cuidados em mangueiras de incêndio. Rio de Janeiro, 2004.

AZEVEDO NETTO, J. M.; FERNANDEZ, M. F.; ARAÚJO, R.; ITO, A. E. Manual de Hidráulica. 8.ed. São Paulo: E. Blucher, 1998.

BRASIL. Instituto Brasileiro de Geografia e Estatística (IBGE). Médias de altura e peso da população. Disponível em:

$<$ http://www.ibge.gov.br/home/estatistica/populacao/condicaodevida/pof/2008_2009_en caa/tabelas_pdf/tab1_1.pdf $>$. Acesso em: 28 abr. 2011.

FOX, ROBERT W.; MCDONALD, ALAN T.; PRITCHARD, PHILIP J. Introdução à Mecânica dos Fluídos. 6.ed. Rio de Janeiro: LTC, 2004.

NATIONAL FIRE PROTECTION ASSOCIATION. NFPA 14: Standard for the Installation of Standpipe and Hose Systems. Atlanta, 2003.

PARANÁ. Polícia Militar do Paraná. Comando do Corpo de Bombeiros. Código de Segurança Contra Incêndio e Pânico. Curitiba, 2011.

PARANÁ. Polícia Militar do Paraná. Comando do Corpo de Bombeiros. Manual de Combate a Incêndios. Curitiba, 2008.

SEITO, A. I. et al. A Segurança Contra Incêndios no Brasil. São Paulo: Projeto Editora, 2008.

TIPLER, P. A. Física para engenheiros e cientistas. 4. ed. Rio de Janeiro: LTC, 2000. 